\title{
Optimal Allocation and Sizing of DG in Radial Distribution System- A Review
}

\author{
Ponnapureddy Niveditha ${ }^{1}$ and Dr. M. S Sujatha ${ }^{2}$ \\ ${ }^{1}$ PG Scholar, EEE, Sree Vidyanikethan Engineering College, India \\ ${ }^{2}$ Professor, EEE, Applied Renewable Energy Research Lab, \\ Sree Vidyanikethan Engineering College, India \\ Iniveponnapureddy479@gmail.com
}

\begin{abstract}
Distributed Generation (DG) plays a vital role in modern power systems to achieve the requirements and satisfaction of end users while transmitting and distributing power from one to another point. It is a small scale generation which is also known as the embedded generation, dispersed generation or the decentralized generation. The optimal allocation of distributed generation $(D G)$ on distributed network plays a crucial role in maximizing the benefits such as reduction of network losses and voltage profile improvement. There are many techniques used for the optimal allocation and sizing of DG in Radial Distribution System (RDS). The paper presented an overview and review the techniques used in some of the most popular methods includes load flow based methods, numerical techniques, intelligent techniques and evolutionary techniques. The evolutionary techniques include various optimization techniques such as Genetic Algorithm (GA), Particle Swarm Optimization (PSO), Artificial Bee Colony (ABC) and Ant Colony Optimization and so on. The paper also provides advantages and disadvantages of each method and useful guidelines for the further research in this area.
\end{abstract}

Keywords: Distributed Generation (DG), Radial Distribution Systems (RDS), voltage profile improvement, and reduction of losses

\section{Introduction}

The electric power generation units placed near to the load and connected directly to the distribution networks defined as DG. To meet the ever-increasing demand for electricity, various technologies are used. The different types of Distributed Generation (DG) technologies include Combined Heat Power (CHP) also known as cogeneration or trigeneration, fuel cells, wind power systems, photovoltaic systems (typically rooftop solar PV) and hybrid power systems (solar hybrid and wind hybrid systems). Distributed generation covers a large variety of locally installed power generation units which can be of both renewable and conventional types. Among those technologies, Distributed Generation (DG) is one. The DG units are used for the industrial, commercial and domestic applications.

Distributed Generations are classified into four types. They are

1. Type-1: DG capable of injecting real power only

2. Type-2: DG capable of injecting reactive power only

3. Type-3: DG capable of injecting both real and reactive power

4. Type-4: DG capable of injecting real but consuming reactive power

Received (January 10, 2018), Review Result (April 30, 2018), Accepted (May 7, 2018) 
Photo-voltaic, fuel cells are good examples of Type-1. Capacitors, KVAR compensator, synchronous compensator are examples of Type-2. Synchronous machines are the example of Type-3. For the location and sizing of DG the important constraints to be considered are voltage limit, real power limit, reactive power limit, power flow limit, number of DG units and size of DG units. If the Distributed Generation (DG) units are improperly allocated and sized the reverse power flow from DG units can led to higher system losses, voltage fluctuations and increase in cost. By identifying the proper position of DG units and placing the DG at an optimum location with ideal capacity and type of DG unit the advantages are increased. Distribution generation allows collection of energy from many sources and may give lower environmental impacts and improved security of supply. The benefits of DG at optimal location and size are voltage improvement, minimization of real and reactive power losses, enhancement of system efficiency, and increase in system reliability, improving the power factor of the system and therefore improving the power quality of the system.

\section{Review of Literature}

The following literature provides the summary and application of each in the optimal location of Dispersed Generation in the power system network. The strengths and weakness of each method highlighted.

\section{A. Load Flow-Based Methods}

The power-flow study, or load-flow study, is a numerical analysis of the flow of electric power in an interconnected system. The load flow method is also known as power flow method. The steady-state operating point of the power system can found by using load flow or power flow method. The aim of the load flow or power flow is to obtain all bus voltages and complex power flowing through all network components. There are various load flow based methods such as Gauss-seidel method, Newton-Raphson method and Backward/Forward sweep load flow method. The load-flow using Newton-Raphson method has two methods of solutions, the first is Rectangular co-ordinates method and second is polar co-ordinates formulation.

A. Kazemi and M. Sadeghi, et. al., in the year 2009[1] have introduced a load flow based method for the optimal location of Dispersed Generation (DG). It is necessary to determine the location and size of DG in a radial distribution system to improve the voltage profile of the system. Here the proposed method, i.e. load flow algorithm is used to improve the voltage profile of the system, but it is not used for small systems. Due to many constraints, the preeminent site may not always be possible. By using a DG, there are many advantages such as voltage profile improvement; the efficiency of the system increases and the line losses gets reduced.

In the year 2012, Nibedita Ghosh, Sharmistha Sharma et.al., [2] has discussed the Load Flow-based Approach for Optimum Allocation of Distributed Generation Units in the Distribution Network for Voltage Improvement and Loss Minimization. DG allocation is a vital factor. The DG units are improperly allocated which can cause low or overvoltage in the system. By the optimum allocation of DG, there is a variety of benefits. The authors have used ETAP software to determine the optimum allocation and sizing of DG in a radial distribution system to reduce the losses and improve voltage profile. Here power cost and power ratings of DG are taken into consideration.

\section{B. Numerical Techniques}

There are various statistical techniques such as analytical methods, linear programming methods, and non-linear programming methods. 
Caisheng Wang, M. Hashem Nehrir, et.al., [3] in 2004, has discussed the analytical approach to determine the optimal location and size of DG in the radial for the minimization of system power losses. By the placement of DG in proper location there are most potential benefits. The Analytical Approach is used to find the optimal location and size of DG both in the radial as well as networked systems. Here there is no use of iterative algorithms like load flow programs. Therefore, there is no convergence problem involved in this method.

Dr. A. Lakshmi Devi, A. Chaithanya, et.al., [4] has discussed a new analytical method for the sizing and sitting of DG in the radial system in 2012. It is based on the features of the distribution system such as wide range of $X / R$ ratio, the vast number of nodes and radial structure. But for the transmission systems, the conventional techniques fail to determine the optimal location and size of DG. Here the loss sensitivity factor is used based on current injection method. The optimum size and location of DG are calculated by using sensitivity factor to reduce the total power losses by an analytical approach. There is no use of the Jacobian matrix, admittance matrix, and inverse admittance matrix. The advantage of the method is, it is faster than other methods in computation time.

In 2015 Rajkumar Viral, D.K. Khatod, et.al., [5] has discussed the analytical approach for the optimal allocation and sizing of DG units in the balanced radial distribution network to minimize the power loss of the system. The minimizations of losses are based on the active and reactive components of branch currents by the placing of DG at various locations. The advantage of the method is, it uses Self Correction Algorithm (SCA) which requires less number of iterations to achieve the convergence and hence demand less computation time. Another benefit is the total number of load flow used remains typically unchanged for larger systems. The drawback of the method is, it is not applicable for the unbalanced and meshed distribution system.

N. Ramya, T. Padmavathi, et.al., [6] has discussed the Optimal DG allocation and sizing in a Radial Distribution System using Analytical Approach in 2015. A conventional Backward and Forward Sweep Approach and loss reduction techniques have been used for the DG location and sizing in a Radial Distribution System. The method also minimizes the total real power losses by the optimal location of DG. Here an exact loss formula has to be considered for DG placement. All the analysis can be done by using forward and backward approach. The sizing and allocation were purely based on minimal or optimal real power losses for various bus locations. By using the Exact Loss Formula, the power losses were estimated at different power factors.

In the year 2016, E. K. Bindumol and C. A. Babua, et.al., [7] has discussed the Analytical and sensitivity approaches for the sizing and placement of single DG in radial system. By the use of Distributed Generators especially, wind and solar systems to the grid has been steadily increasing due to the apprehension of a hygienic environment. Here a new fast and straightforward load flow algorithm named Backward Forward Sweep Algorithm (BFSA) is used for finding the voltage profile and power losses with the addition of various sizes of DG at different locations. GA based BFSA is adopted in finding the optimal location and sizing of DG to attain an improved voltage profile and considerable reductionof power loss.

\section{Evolutionary Techniques}

The Evolutionary techniques are used to solve complex problems. Here the evolutionary algorithms involve a biological process. There are various evolutionary techniques such as Genetic Algorithm, Particle Swarm Optimization, Artificial Bee Colony Optimization, and Ant Colony Optimization, Artificial Bee Colony (ABC) Optimization and so on.

Gianni Celli, Member, Emilio Ghiani, et.al., [8], the multi-objective formulation for the sitting and sizing of DG resources into existing distribution networks is proposed in the year 2005. The methodology adopted permits the planner to decide the best 
compromise between cost of network upgrading, cost of power losses, cost of energy not supplied, and cost of energy required by the served customers. The implemented technique is based on a genetic algorithm and an $\varepsilon$-constrained method that allows obtaining a set of non-inferior solutions.

T. N. Shukla, S. P. Singh, et.al., in 2010 [9] has discussed the allocation of optimally distributed generation using GA for minimum system losses in radial distribution networks. The distributed generation is one of the possible options for mitigation of problems of load growth, overloading of lines, quality of supply and reliability, in turn extending equipment maintenance intervals and to reduce line losses. Therefore, this paper aims to minimize active power loss by placing DG in a radial distribution system. The loss sensitivity to active power injection at various nodes is used to decide the strategic locations.

Naveen Jain, S.N. Singh, et. al., in 2010 [10] has discussed the Particle Swarm Optimization Based Method for optimal sitting and sizing of multiple distributed generators. In this, the voltage profile improvement, minimization of losses and voltage stability index are considered. By considering the constant power as well as voltagedependent load models using PSO the system losses are minimized.

Fahad S. Abu-Mouti, et. al., [11] has proposed a new optimization algorithm called Artificial Bee Colony (ABC) algorithm in the year 2011. The ABC algorithm is used to find the optimal allocation and sizing of DG in Radial Distribution System (RDS). The $\mathrm{ABC}$ algorithm uses only two parameters for tuning. The proposed method is used for solving mixed-integer nonlinear optimization problems and unconstrained problem.

A.M. El-Zonkoly et. al., [12] has discussed the optimal placement of multi-DG units including different load models using Particle Swarm Optimization (PSO) in the year 2011. The various load models with non-unity power factor with a multi-objective indexbased approach are used to determine the optimal location and size of DG in the radial distribution system. The sizing and sitting of DG can be affected by load models. It considers voltage improvement, the active and reactive power losses of the system, line loading and mega volt-ampere intake by the grid.

Amir Hossein Gandomi, Amir Hossein Alavi et. al., in the year 2012 [13] has described the novel biologically-inspired algorithm, namely Krill Herd $(\mathrm{KH})$ for solving the optimization tasks. The $\mathrm{KH}$ algorithm is based on the simulation of the herding behaviour of the krill individuals. The minimum distances of each krill from food and highest density of the herd is considered as the objective function of the krill movement. The KH algorithm is capable of exploring the search space globally, but it fails to select sometimes the global optimum solution in the search space.

In the year 2013, Ketfi Nadhir, Djabali Chabane, et. al., [14] has used Firefly Algorithm (FA) for solving DG placement and sizing in order to obtain minimum loss, voltage profile improvement, and minimum generation cost. The advantage of firefly algorithm is it can deal with non-linear, multi-model optimization problem naturally and efficiently and it does not require a good initial solution to start its iteration process. The drawback of the algorithm is slow convergence speed.

Mohamed Imran, M. Kowsalya et. al., [15] has proposed a new approach in 2014 to find the optimal location and size of Distributed Generation (DG). Bacterial Foraging Optimization Algorithm (BFOA) is a swarm intelligence technique is used for the minimization of network power losses, improving voltage stability and operational cost. The proposed technique is very accurate in finding the optimum solutions and this work can also be implemented for all systems with $n$ number of buses and all types of loads. The drawback of the BFOA is the complication of the algorithm and hence less convergence speed. 
Table 1. Comparative Results of GA, PSO, and SA with BFOA

\begin{tabular}{|c|c|c|c|c|c|c|}
\hline Method & $P_{\text {DG,Toss }}(K W)$ & $\begin{array}{c}\text { \%Loss } \\
\text { reduction }\end{array}$ & $V_{\text {worst }}($ p.u. $)($ bus $)$ & $\begin{array}{c}\text { DG } \\
\text { location }\end{array}$ & $\begin{array}{c}\text { DG } \\
\text { size }\end{array}$ & $\begin{array}{c}\text { Power } \\
\text { factor }\end{array}$ \\
\hline GA & 106.30 & 49.61 & 0.9809 & 11 & 1.5000 & \\
& & & & 29 & 0.4228 & unity \\
& & & & 30 & 1.0714 & \\
\hline PSO & 105.35 & 50.06 & 0.9806 & 13 & 0.9816 & \\
& & & & 32 & 0.8297 & unity \\
& & & & 8 & 1.1768 & \\
\hline SA & 82.03 & 61.12 & 0.9676 & 6 & 1.1124 & unity \\
& & & & 18 & 0.4874 & \\
& & & & 30 & 0.8679 & \\
\hline BFOA & 37.85 & 82.06 & 0.9802 & 14 & 0.6798 & unity \\
& & & & 18 & 0.1302 & \\
& & & & 32 & 1.1085 & \\
\hline
\end{tabular}

The comparative results of Genetic Algorithm (GA), Particle Swarm Optimization (PSO), and Simulated Annealing (SA) with Bacterial Foraging Optimization Algorithm (BFOA) are shown in the table1. The BFOA gives better results when compared with the optimization techniques such as GA, PSO, and SA. The BFOA reduces the total power losses, improves voltage profile and reduces the size of the DG.

In the year 2014, M.F. Sulaima, N.F. Napis, M. K. M. Nor, et.al., [16] has discussed that the losses in the network can be minimized by using Distribution Network Reconfiguration (DNR) and sizing the DG. In determining the optimal sizing of DG and identifying the switching operation plan for network reconfiguration, an optimization method which is called as Rank Evolutionary Particle Swarm Optimization (REPSO) will be introduced. The objective is to minimize the total power losses in a radial distribution network and to find the size of DG. The drawback of the REPSO is poor convergence speed.

S. Kumar, D. Pal, et. al., [17] has discussed in the year 2014, the optimal allocation of multiple DG units in Radial Distribution System (RDS) using Modified Differential Evolution Technique. In this paper the DG units are integrated with the conventional radial distribution system, it provides several advantages like reduction of power losses, voltage improvement and the reliability of the system gets increased. By increasing the parameters variable the number of DG units gets increased. By this, the convergence of the objective function gets increased. The advantage of the method is it can handle more certain parameters.

In the year 2015, D. Rama Prabha, et. al., [18] has discussed the optimal location and sizing of DG unit to minimize the total line losses of the radial distribution network using Intelligent Water Drop (IWD) algorithm. For installation of DG units, Loss sensitivity factor is used. IWD is nature-inspired optimization approach in which a natural river always finds an easier path to flow from source to destination when the entire paths are available. The main advantage of the proposed technique is that it is easy to implement and capable of finding the feasible solution. The drawback of this algorithm is that the results are near optimal.

Snigdha Rani Behera, Soumya Prakash Dash, et. al., [19] has discussed in 2015 the problem of optimization for position and size of the DG in radial distribution system using Bat Algorithm. The algorithm is used for voltage profile improvement and reduction of real power losses. The algorithm used for the radial distribution system is based on constant power load per hour and load variation on a 24-hour basis. The optimization technique using Bat Algorithm is more efficient when compared with other optimization techniques such as GA, PSO for real loss power reduction. 
Table 2. Comparative Results of PSO, SGA with BAT Algorithm

\begin{tabular}{|c|c|c|c|c|}
\hline Algorithm used & & No DG & $1 \mathrm{DG}$ & 2 DG \\
\hline \multirow[t]{3}{*}{ PSO } & $\begin{array}{l}\text { Objective function value } \\
\left(P_{\text {Losses }} \boldsymbol{i n} \boldsymbol{M W} \boldsymbol{W}\right)\end{array}$ & \multirow{3}{*}{0.225} & 0.0838 & 0.0788 \\
\hline & DG position & & 61 & 14,62 \\
\hline & DG size (MW) & & 2.0 & $0.7,2$. \\
\hline \multirow[t]{3}{*}{ SGA } & $\begin{array}{l}\text { Objective function value } \\
\left(\boldsymbol{P}_{\text {Losses }} i n \boldsymbol{M} \boldsymbol{W}\right)\end{array}$ & \multirow{3}{*}{0.225} & 0.0894 & 0.0829 \\
\hline & DG position & & 61 & 17,61 \\
\hline & DG size (MW) & & 2.3 & $1.000,2.400$ \\
\hline \multirow[t]{3}{*}{ BAT Algorithm } & $\begin{array}{l}\text { Objective function value } \\
\left(P_{\text {Losses }} \operatorname{in} \boldsymbol{M} \boldsymbol{V}\right)\end{array}$ & \multirow{3}{*}{0.225} & 0.0832 & 0.0759 \\
\hline & DG position & & 61 & 61,18 \\
\hline & DG size (MW) & & 1.901 & $1.4756,0.04242$ \\
\hline
\end{tabular}

Table 2 shows the comparative results of PSO, SGA with BAT Algorithm. The BAT Algorithm shows better results when compared with PSO and SGA. The comparison is done for the objective function value (power losses in MW), DG position and DG size (MW). The losses gets reduced, size of the DG gets reduced by using the BAT Algorithm.

In the year 2015, Priyanka Das et.al [20] has discussed the optimal sizing and placement of distributed generation in a radial distribution system using Loss Sensitivity Factor and Firefly Algorithm. Here a two-stage method has proposed for the optimal allocation of DG in a Radial Distribution System. Firstly loss sensitivity factor is used to find the optimal location and secondly, the Firefly Algorithm is used to find the optimal size of the DG for the minimization of losses. Combination of LSF and FA gives good results.

MohammadrezaVatani, DavoodAlkaran, et. al., in 2015 [21] has discussed the multiple DG units allocation in the distribution network for loss reduction based on a combination of analytical and genetic algorithm methods. The method is used to reduce the system losses. Here GA is used to find the optimal location for the DGs installation and analytical method is used to determine the DG capacities. The convergence accuracy and speed are guaranteed by this combination. During loss reduction the DGs power factor, active power and losses are considered.

\section{Table 3. Comparative Results of IA, LSF, ELF with Combination of} Analytical and Genetic Algorithm

\begin{tabular}{|c|c|c|c|c|c|}
\hline $\begin{array}{c}\text { Number } \\
\text { of DG }\end{array}$ & Method used & $\begin{array}{c}\text { Location } \\
\text { bus }\end{array}$ & $\begin{array}{c}\text { Power } \\
\text { KW }\end{array}$ & $\begin{array}{c}\text { Power } \\
\text { factor }\end{array}$ & $\begin{array}{c}\text { Loss } \\
\text { KW }\end{array}$ \\
\hline 1 & LSF & 18 & 743 & 1 & 146.82 \\
\hline 1 & IA & 6 & 2601 & 1 & 111.1 \\
\hline 1 & ELF & 6 & 2601 & 1 & 111.1 \\
\hline 1 & Proposed method & 6 & 2706.73 & 1 & 99.22 \\
\hline
\end{tabular}

The comparative results of Loss Sensitivity Factor (LSF), Improved Analytical (IA), and Exhaustive Load Flow (ELF) methods with the proposed method i.e., combination of the analytical and Genetic Algorithm (GA) are shown in table 3. Here the losses of LSF, IA, and ELF are 146.82, 111.1 and $111.1 \mathrm{~kW}$. By using the proposed method the losses get reduced to $99.22 \mathrm{~kW}$.

Xiaoyu Sun, Jinsong Liu, Xin Sun, et.al in 2016 [22] has introduced the optimization of distribution network with distributed generation based on an improved Genetic Algorithm. The mathematical model of distribution network can be established by using constraints and objective function, which contains the network loss, the DGs investment 
and reliability of power supply. This paper gives a design of IGA (Improved Genetic Algorithm). By the combination of a conventional distribution network, a distribution network with distributed generation not only makes full use of renewable energy but also decreases the use of fossil fuel and increases the reliability of power supply. To optimizing power flow and distribute more power, a model of the distribution network is designed based on reliability. Compared with the general genetic algorithm, the improved genetic algorithm adds a section that modifies weight factor of distributed generations.

Sarfaraz1, Dr. Ajay Bansal, et. al., [23] has discussed the optimal allocation and sizing of distributed generation for power loss reduction in 2016. The optimal DG placement (OPDG) method is used to provide the best locations and sizes of DGs to optimize electrical distribution network operation taking into account DG capacity and voltage constraints. Here an efficient Selective Particle Swarm Optimization is used to determine the best location of DG in a radial distribution system. For active power loss reduction and voltage profile enhancement, the objective function is considered for determining the optimal location of DG in the distribution network. The SPSO not only reduces line losses but also reduces the size of DGs with permissible voltage limits.

Aashish Kumar Bohre, Ganga Agnihotri, et. al., [24] has discussed in 2016 the optimal sizing and sitting of DG with load models using soft computing techniques in the possible distribution system. Here an effective methodology is developed to develop the technology as well as economic benefits. A Multi-Objective Function (MOF) is developed for the performance evaluation such as active and reactive power index, voltage deviation index, and reliability index and shift factor. A MOF has been solved the optimal location and sizing of DG using Genetic Algorithm (GA) and Particle Swarm Optimization (PSO). The method is efficient and reduces the power losses, voltage improvement, decrease ENS, enhance reliability, increase ATC and load balancing capability of the system.

E.K. Bindumol and C.A. Babua, et. al., [25] have discussed the analytical and sensitivity approaches for the sizing and placement of single DG in radial system. A new simple and fast load flow based algorithm known as Backward/Forward Sweep algorithm for finding the voltage profile and total losses by the integration of DG at different locations. Genetic Algorithm based BFSA is used to find the optimal location and size of DG. The advantage is the reduction of total power losses and improvement in voltage profile.

A. Marimuthu, Dr. K. Gnanambal, et.al [26] has discussed the optimal allocation and sizing of DG in a Radial Distribution System (RDS) by using Whale Optimization Algorithm in 2017. The optimum location and size of DG have created collision on voltage profile, system power losses, and voltage stability. In this work, the Whale Optimization Algorithm technique is considered with a multi-objective function to determine the location and size of DG. The algorithm can find the solutions with better quality for more extensive systems computational efficiency.

Table 4. Comparative Results of Genetic Algorithm (GA) with Whale Optimization Algorithm (WOA)

\begin{tabular}{|c|c|c|c|c|c|c|}
\hline Algorithm & $\begin{array}{c}\text { DG } \\
\text { location }\end{array}$ & $\begin{array}{c}\text { DG size } \\
\text { (kW) }\end{array}$ & $\begin{array}{c}\text { Power } \\
\text { loss } \\
\text { without } \\
\text { DG(kW) }\end{array}$ & $\begin{array}{c}\text { Power } \\
\text { loss with } \\
\text { DG } \\
\text { (kW) }\end{array}$ & $\begin{array}{c}\text { \%Power } \\
\text { loss } \\
\text { reduction }\end{array}$ & $\begin{array}{c}\text { Power } \\
\text { Factor }\end{array}$ \\
\hline \multirow{2}{*}{ GA } & 11 & 495.1 & & & & 0.8140 \\
& 18 & 378.0 & 224.9 & 4.795 & 97.10 & 0.8250 \\
\hline \multirow{2}{*}{ WOA } & 61 & 1674.0 & & & & 0.8130 \\
\hline & 11 & 497.3 & & & & 0.8213 \\
& 61 & 380.2 & 224.9 & 4.672 & 98.08 & 0.8159 \\
\hline
\end{tabular}


The comparative results of GA with Whale Optimization Algorithm are shown in the table 4. By using the WOA the \% power loss reduction is 98.08 . The losses gets reduced and Power factor gets improved.

Vadimgadu Roja, DR. M.S. Sujatha in the year 2016 [27] has discussed a review of Optimal DG Allocation in Distribution System for Loss Minimization. The authors have discussed state of the art techniques for optimum placement and sizing of DG have been suggested. The paper provides an overview of the various methods implemented for determining optimal location and capacity of DG units to maximize the benefits of DG units in the system network. The most common objective function is the minimization of real power losses, reactive power losses and voltage profile improvement. Here they concluded that numerical and analytical methods are more time consuming and they are not sufficient to solve the problem for optimal allocation and size of DG sources in the system.

\section{Discussion}

The strengths and weaknesses of different research studies to find the optimal location and size of DG had reviewed in the paper. Each technique has considered different objective function and constraints to solve the problem. Exact comparisons between the solutions of various techniques are difficult however some objectives causes a reduction in losses, cost, and improvement in voltage profile are common in most of the topics. The drawbacks of some of the methods such as firefly algorithm has poor convergence speed, Bacterial Foraging Optimization Algorithm (BFOA) has complexity of the algorithm, and poor convergence speed, Invasive Weed Optimization (IWO) has the solutions which are near optimal, analytical method is not applicable for meshed and unbalanced distribution systems, Rank Evolutionary Particle Swarm Optimization (REPSO) has poor convergence speed, Modified Firefly Algorithm has poor convergence speed, Krill Herd Algorithm fails to select the optimum solution in the search space.

\section{Conclusion}

The paper presented the overview and key issues of various research studies for optimal allocation and sizing of Distributed Generation (DG) in a radial distribution system. Improper Allocation and size of DG not only causes the system loses, but it also causes jeopardise the system operators. DG should be placed in the optimal location to provide technical, economic and environmental benefits. Optimal placement and sizing of DG is a complex problem. From the literature, it is clear that there are various solutions for this problem. To overcome the drawbacks of existing methods; the researchers can concentrate on hybrid techniques like a combination of Krill Herd and Genetic Algorithm, etc.

\section{References}

[1] A. Kazemi and M. Sadeghi, "A Load Flow Based Method for Optimal Location of Dispersed Generation Units", (2009).

[2] N. Ghosh, S. Sharma and S. Bhattacharjee, "A Load Flow based Approach for Optimum Allocation of Distributed Generation Units in the Distribution Network for Voltage Improvement and Loss Minimization", International Journal of Computer Application, vol. 50, no. 15, (2012).

[3] C. Wang and M. Hashem Nehrir, "Analytical approaches optimal allocation of Distributed Generation (DG) in power systems", IEEE Transactions on Power Systems, vol. 19, no. 4, (2004).

[4] A. Lakshmi Devi and A. Chaithanya, "A New Analytical Method for the sizing and siting of DG in Radial System of Minimize Real Power Losses", International Journal of Computational Engineering Research, vol. 2, no. 7, (2012).

[5] N. Ramya and T. Padmavathi, "Optimal DG allocation and sizing in a Radial Distribution System using Analytical Approach", International Journal of Science, Engineering and Technology Research (IJSETR), vol. 4, no. 2, (2015). 
[6] R. Viral and D. K. Khatod, "An analytical approach for sizing and siting of DGs in balanced radial distribution networks for loss minimization”, Electra. Power Energy Syst., vol. 67, (2015), pp. 191-201.

[7] E. K. Bind Mol and C. A. Babua, "Analytical and sensitivity approaches for the sizing and placement of single DG in radial system", Advances in Energy Research, vol. 4, no. 2, (2016), pp. 163-176.

[8] G. Celli, Member, E. Ghiani, S. Mock and F. Pilo, "A Multi-objective Evolutionary Algorithm for the Sizing and Siting of Distributed Generation", IEEE Transactions On Power Systems, vol. 20, no. 2, (2005) May.

[9] T. N. Shukla, S. P. Singh and K. B. Naik, "Allocation of optimal distributed generation using GA for minimum system losses in radial distribution networks", International Journal of Engineering, Science and Technology, vol. 2, no. 3, (2010), pp. 94-106.

[10] N. Jain, S. N. Singh, Senior Member and S. C. Srivastava, "Particle Swarm Optimization Based Method for Optimal Siting and Sizing of Multiple Distributed Generators", 16thNational Power Systems Conference, (2010) December 15th-17th.

[11] F. S. Abu-Mouti and M. E. El-Hawary, "Optimal Distributed Generation Allocation and Sizing in Distribution Systems via Artificial Bee Colony Algorithm", IEEE Transactions On Power Delivery, vol. 26, no. 4, (2011) October.

[12] A. M. El-Zonkoly, "Optimal placement of multi- DG units including different load models using Particle Swarm Optimization (PSO)", IET Generation, Transmission and Distribution, vol. 5, no. 7, (2011), pp. 760-771.

[13] A. Hossein Gandomi and A. Hossein Alavi, "Krill herd: a new bio-inspired optimization algorithm", Int. J. Commun. Nonlinear Sci. Numer. Simul., vol. 17, (2012), pp. 4831-4845.

[14] K. Nadhir, D. Chabane and B. Tarek, "Distributed generation and location and size determination to reduce power losses of a distribution feeder by Firefly Algorithm", International Journal of Advanced Science and Technology, vol. 56, (2013), pp. 61-72.

[15] A. Mohamed Imran and M. Kowsalya, "Optimal size and siting of multiple distributed generators in distribution system using bacterial foraging optimization, Swarm Evolutionary Computer", vol. 15, (2014), pp. 58-65.

[16] M. F. Sulaima, N. F. Napis, M. K. M. Nor, W. M. Dahalan and H. Mokhlis, "DG sizing and DNR based on REPSO for power losses reduction", IEEE 8th International Power Engineering Optimization Conference, (PEOCO), (2014), pp. 99-104.

[17] S. Kumar, D. Pal, K. K. Mandal and N. Chakraborty, "Optimal allocation of multiple DG units in Radial Distribution System (RDS) using Modified Differential Evolution Technique”, International Conference on Control, Instrumentation, Energy and Communication, (2014).

[18] D. Rama Prabha and T. Jayabarathi, "Optimal placement and sizing of multiple distributed generating units in distribution networks by invasive weed optimization algorithm", Ain Shams Eng. J., (2015).

[19] S. Rani Behera, S. Prakash Dash and B. K. Panigrah, "Optimal Placement and Sizing of DGs in Radial Distribution System (RDS) using Bat Algorithm", International Conference on Circuit, Power and Computing Technologies [ICCPCT], (2015).

[20] P. Das, "Optimal Sizing and Placement of Distributed Generation in a Radial Distribution System Using Loss Sensitivity Factor And Firefly Algorithm", International Journal of scientific research and management (IJSRM), vol. 3, no. 4, (2015), pp. 2611-2618.

[21] M. Vatani and D. Alkaran, "Multiple DG units allocation in distribution network for loss reduction based on a combination of Analytical and Genetic Algorithms", IETGeneration, Transmission and Distribution, (2015) September, pp. 1-7.

[22] X. Sun, J. Liu, X. Sun and J. Hu, "Optimization of Distribution Network with Distributed Generation Based on an Improved Genetic Algorithm", International Journal of Grid and Distributed Computing, vol. 9, no. 1, (2016), pp. 105-116.

[23] A. Bansal Sarfaraz and S. Singh, "Optimal Allocation and Sizing of Distributed Generation for Power Loss Reduction", International Conference \& Workshop on Electronics and Telecommunication Engineering, (2016).

[24] A. Kumar Bohre, G. Agnihotri and M. Dubey, "Optimal sizing and siting of DG with load models using soft computing techniques in practical distribution system", IET Generation, Transmission and Distribution, (2016) March, pp. 11-16.

[25] E. K. Bindumol and C. A. Babua, "Analytical and sensitivity approaches for the sizing and placement of single DG in radial system", Advances in Energy Research, vol. 4, no. 2, (2016), pp. 163-176.

[26] A. Marimuthu, K. Gnanambal and R. Priyanka, "Optimal allocation and sizing of DG in Radial Distribution System using Whale Optimization Algorithm", IEEE International Conference on Innovations in Green Energy and Healthcare Technologies, (2017).

[27] V. Roja and M. S. Sujatha, "A Review of Optimal Allocation in Distribution System for Loss Minimization", IOSR Journal of Electrical and Electronics Engineering, (2016), pp. 15-22. 
International Journal of Grid and Distributed Computing

Vol. 11, No. 6 (2018) 